\title{
FLORES, G. G. Horácio. Arte Poética. Tradução, introdução e notas de Guilherme Gontijo Flores. Belo Horizonte: Autêntica Editora, 2020.
}

\section{Novas e velhas discussões na obra do magister satiricus: a Arte Poética de Horácio em 'hexâmetros brasileiros'}

Alexandre Pinheiro HASEGAWA ${ }^{1}$

\section{http://dx.doi.org/10.21165/gel.v18i2.3121}

Guilherme Gontijo Flores, que anuncia tradução completa das obras de Horácio (p. 31), inaugura o projeto com a Arte Poética (daqui em diante $A P$ ), também conhecida como Epístola aos Pisões ou ainda Epístolas 2.3. A obra, com prefácio de Brunno Vinicius Gonçalves Vieira (p. 11-12), está dividida em quatro partes, excluindo as informações sobre o tradutor ao fim (p. 171): 1) texto introdutório, intitulado "Um regulador esquivo" (p. 13-37); 2) o texto latino da $A P$ ao lado da tradução (p. 40-73); 3) notas sobre o texto e a tradução (p. 77-137), e 4) bibliografia em que o autor elenca os títulos que usa para o estudo e tradução de toda a obra de Horácio (p. 143-170). A resenha, portanto, será dividida nestas mesmas partes, em que procuro discutir os aspectos principais da publicação, sem deixar, porém, de listar ao fim de cada uma o que talvez deva ser corrigido para a segunda edição.

\section{O ensaio introdutório “Um regulador esquivo"}

Alguns aspectos - quase como topoi nos estudos sobre a $A P$ - sempre são discutidos por quem se dedica a este texto tão fundamental do corpus horaciano, a saber: o título, a data de composição e/ou publicação, os destinatários (os Pisões), a organização do texto e o gênero. Tais tópicos dominam os estudos da $A P$, escrita em hexâmetros datílicos, com 476 versos, constituindo-se como o mais longo poema de Horácio. O autor também passa por todos esses assuntos. Os três primeiros (título, datação e destinatários), sobre os quais ainda temos muitas dúvidas, sem que haja acordo entre os estudiosos, são tratados mais brevemente. Assim, Flores, junto com parte da crítica, situa a obra no fim da carreira do poeta, em torno de 10 a.C. (p. 17); entende que os Pisões são, mais provavelmente,

1Universidade de São Paulo, São Paulo, São Paulo, Brasil; ahasegawa@usp.br; https://orcid.org/0000-0002-3275-0629 
o pontífice Lúcio Calpúrnio Pisão e dois filhos deste (p. 15-16), e segue o título mais conhecido, Arte Poética, já presente em Quintiliano (séc. I d.C.) - autor não tão distante de Horácio no tempo -, na Formação do Orador (8.3.60: tale monstrum quale Horatius in prima parte libri de arte poetica) $)^{2}$.

Embora os três pontos sejam questões ainda subjudice, julgo que estudos recentes (e não tão recentes), que Flores parece desconhecer, trouxeram importantes contribuições para o debate, sobretudo em relação aos destinatários, a saber: a) FRISCHER, B. Shifting Paradigms: New Approaches to Horace's Ars Poetica, Atlanta (GA): Scholars Press, 1991, esp. p. 5-59; b) ARMSTRONG, D. The Addressees of the Ars poetica: Herculaneum, the Pisones and Epicurean Protreptic, MD ('Mega nepios: Il destinatario nell'epos didascalico'), v. 31, p. 185-230, 1993; c) GEUE, T. Editing the Opposition: Horace's Ars Politica, MD ('New Approaches to Horace's Ars poetica'), v. 72, p. 143-72, 2014; d) FERRISS-HILL, J. (2019). Horace's Ars Poetica. Family, Friendship, and the Art of Living. Princeton \& Oxford: Princeton University Press, 2019, esp. p. 5-22 e Cap. 2 ('Pisones'), p. 100-153. Não é o caso de detalhar todos os argumentos aqui, mas parece-me importante atualizar, em parte, a discussão sobre a $A P$, que progrediu bastante desde o fundamental estudo e monumental comentário de Brink (1963 e 1971) e o mais breve de Rudd (1989), três das principais obras usadas por Flores.

Fugindo da oposição entre o pontífice Lúcio Calpúrnio Pisão ${ }^{3}$ e Cneu Calpúrnio Pisão, Frischer (1991, p. 5-59), em estudo polêmico e já bem discutido ${ }^{4}$, baseado em parte em estatísticas, propõe que a epístola foi composta entre 24-20 a.C. e dirigida a Lúcio Calpúrnio Pisão Cesonino e seus dois filhos, entre os quais o pontífice Lúcio Calpúrnio Pisão, que foi poeta e cônsul em 15 a.C. A proposta, se não pôs fim à discussão, trouxe novos modos de ver e abordar a questão. Ora, Armstrong, retomando Frischer, não decide por Cesonino ou pelo pontífice como o pai referido na $A P$, mas pensa ser importante a ligação que ambos têm com o poeta e filósofo epicurista Filodemo de Gádara, que lhes teria deixado a biblioteca na villa de Herculano e é o autor de quem talvez Horácio tenha tomado as lições de Neoptólemo de Pário sobre poética.

\footnotetext{
2 Além desta passagem, mencionada na obra (p. 15), há outra, logo no início da Formação do Orador (Epístola a Trifão, 2), que poderia ainda ser discutida: "usus deinde Horati consilio, qui in arte poetica suadet ne praecipitetur editio 'nonumque prematur in annum' [...].". Ferriss-Hill (2019, p. 12) propõe ainda o título humano capiti, as duas palavras iniciais da $A P$, já que as obras na Antiguidade eram também conhecidas pelas suas primeiras palavras, como a Eneida, simplesmente referida como arma uirumque (ver Ovídio, Tristezas 2.534).

3 Uma das dificuldades para identificar o pai da $A P$, a quem Horácio se dirige, com o pontífice Lúcio Calpúrnio Pisão - identificação feita, primeiramente, por Porfirião (HOLDER, 1979, p. 162) -, é o fato de que não temos notícia de ele ter tido filhos.
}

4 Ver as resenhas de Mayer (1992) e Muecke (1993), por exemplo. 
Geue, por sua vez, defende que se trata de Cneu Calpúrnio Pisão, que certamente foi pai de dois filhos ${ }^{5}$; inicialmente, aliou-se a Cássio e Bruto, mas, derrotado na batalha de Filipos, foi posteriormente perdoado por Augusto e tornou-se cônsul em 23 a.C. Embora Flores admita (p. 16) que não se pode desconsiderar a possibilidade de ser Cneu Calpúrnio Pisão, afirma que "nada nessa parte da família Pisão parece aproximá-los da poesia ou de Horácio especificamente". Ora, embora Geue enfatize a leitura política, vendo a $A P$ como discurso contra a família Pisão e em defesa do regime augustano, é evidente a relação entre Horácio e Cneu Calpúrnio Pisão, não tão explorada até o momento: ambos se aliaram a Bruto e Cássio, ambos foram derrotados na batalha de Filipos (ver Odes 2.7) e perdoados por Augusto: um tornou-se poeta do regime e o outro cônsul em 23 a.C. Assim, não se trata de repassar simplesmente diversas perspectivas para tão complicada questão, mas dar exemplos de como a discussão em Flores sobre o endereçamento na $A P$ poderia ser atualizada, mostrando as novas perspectivas e os avanços importantes em alguns pontos apresentados na obra.

Neste sentido ainda, Ferriss-Hill (2019, p. 104-106) ${ }^{6}$, a mais nova contribuição em extensa monografia, retomando em parte a perspectiva política de Geue, julga que os Pisões são personae. De acordo com a autora, Horácio deliberadamente não identificou, com precisão, seus interlocutores. A meu ver, Flores se beneficiaria muito do segundo capítulo de Ferriss-Hill (2019, p. 100-153), dedicado apenas a discutir os endereçamentos na $A P$, examinando todas as passagens e pensando como o endereçamento a um pai e dois filhos (independentemente da identificação) está relacionado a temas importantes discutidos ao longo da epístola (e.g. a relação entre pai e filhos; entre jovem e velho; entre gerações de homens e palavras etc.), alguns deles já presentes nas Sátiras ${ }^{7}$.

Assim, mais do que se decidir por este ou aquele, valeria a pena observar como o destinatário cumpre um papel importante na organização da obra horaciana, como é evidente, por exemplo, no caso de Mecenas (ver SANTIROCCO, 1984) ${ }^{8}$. Neste sentido, é

\footnotetext{
5 Um dos filhos se tornou questor em 19 ou 18 a.C., não sendo, portanto, muito apropriado o uso de iuuenis, considerando uma datação baixa para a obra (contra GEUE, 2014, p. 145, n. 2). Aqueles que pensam ser Cneu Calpúrnio Pisão o pai, a quem Horácio se dirige na $A P$, defendem, em geral, uma datação mais alta.

6 Esp. p. 105, n. 25: "I consider the Pisones as personae within the poem, just as Horace himself presents a persona in the $A P . "$ Ver também p. 153 e n. 191.

7 Entre outras, vejam-se as seguintes passagens da $A P$ : vv. 60-2: geração das folhas, das palavras e dos homens; vv. 158-178: as quatro idades do homem; vv. 470-2: imagem do filho, poeta louco, mijando sobre as cinzas do pai. Já Geue (2014, p. 159) entendia que "[t]he dynamic between old and young, father and son is a refrain of the Ars that sneaks into the unlikeliest nooks." Nas Sátiras, por exemplo, para a relação entre pai e filho (no caso, o poeta e o próprio pai), ver Sátiras 1.6.

8 Santirocco (1984) se concentra no estudo das Odes, mas Mecenas está presente como importante destinatário nos Epodos (3.20; 9.4; 14.5), nas Sátiras (1.1.1; 1.6.1) e nas Epístolas (1.1.3; 1.19.1).
} 
possível pensar como os destinatários aparecem na $A P$ e discutir se há alguma organização dos endereçamentos no decorrer da obra. Flores, então, propõe (p. 28) que há um "crescendo dos destinatários [...] tanto em força e tamanho quanto em especificidade" ao longo da $A P$, citando os seguintes passos:
v. 5: amici ("amigos"); 9
v. 6: Pisones ("Pisões");
v. 24: pater et iuuenes patre digni ("pai e jovens dignos de tal pai");
vv. 291-2: Vos, o/Pompilius sanguis ("Vós, ó sangue de Pompílio");
vv. 366-7: O maior iuuenum, quamuis et uoce paterna/ fingeris ad rectum [et per te sapis] ("ó mais velho dos jovens, embora pela voz paterna sejas forjado para o reto e saibas por ti mesmo").

Julgo que há alguns problemas nesta proposta. A primeira - e mais importante - é não ter levado em consideração o endereçamento no v. 235 (Pisones), que é idêntico ao do v. 6, rompendo o esquema proposto. Além disso, é discutível se o endereçamento nos vv. 291/2, embora o trecho ocupe o fim de um verso e começo do outro, seja maior que no passo do v. 24, que ocupa todo o segundo hemistíquio do verso, equivalente a três pés e meio, o mesmo espaço métrico ocupado por Vos, o/Pompilius sanguis. Na contagem das sílabas, porém, o trecho do v. 24 (10 sílabas) é maior do que o seguinte (8 sílabas). Do mesmo modo, amici (v. 5) tem o mesmo número de sílabas de Pisones (v. 6). É também discutível se Pisones, o nome da família, seja menos específico do que Vos, o/Pompilius sanguis, perífrase para indicar os Pisões, que formam parte da gens Calpurnia; esses seriam descendentes de Calpo, filho do rei Numa Pompílio. Enquanto nas quatro primeiras passagens, todos os três destinatários estão incluídos, o pai e os dois filhos, na última dirige-se apenas ao mais velho. Enfim, seria importante, portanto, rever a afirmação e o gráfico (p. 28), levando em consideração o que é chamado 'crescendo dos destinatários', tanto em força e tamanho como em especificidade, que parece não corresponder ao que se vê nas passagens elencadas, sobretudo pela ausência do v. 235, excluído da análise.

9 As traduções são nossas. Na passagem do ensaio (p. 28), Flores deixa apenas o texto latino. 
Um ponto importante do ensaio introdutório (esp. p. 18-22), a meu ver, é ter trazido a sátira $(\text { sermo })^{10}$ de novo para discutir a classificação e interpretação da $A P$. Longe de ser

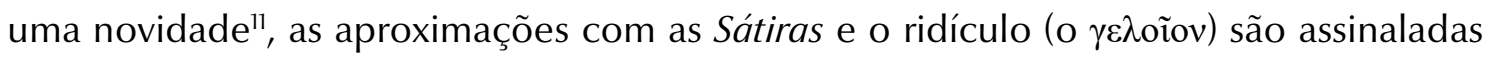
e usadas de muitas maneiras pelos estudiosos da $A P$. Não é o caso de elencar aqui os vários autores que trataram do assunto, mas neste ponto o autor poderia se beneficiar também de algumas das discussões já desenvolvidas pela crítica. Nesta comparação com as sátiras, por exemplo, Hardie (2014, p. 46), seguindo Becker (1963), desenvolve, entre outras ideias, comparação entre o começo e o fim da $A P$ com o início e a conclusão de Sátiras 1.12. Ora, Flores (p. 28) afirma que "a obra tem abertura e encerramento com maior força satírica", sem, contudo, mostrar de modo mais direto a relação com as Sátiras ${ }^{13}$, o que tornaria o argumento mais convincente.

Neste sentido, não é claro o gráfico (p. 28), em que se representam "estruturas importantes que funcionam ao mesmo tempo" na $A P$. Talvez a dificuldade esteja no fato de ser um "esboço simplificado", mas marcam-se como pontos mais altos de "recurso à sátira" a introdução (vv. 1-41) e a parte final, dedicada ao poeta (vv. 295-476). As passagens, de fato, como já mencionado acima, apresentam relações com trechos satíricos do próprio Horácio. Contudo, marca-se como sem recurso à sátira (zero no gráfico) o trecho central

10 Sátiras e Epístolas são descritas como sermones: e.g. ver Epístolas 2.1.4 e 250; Sátiras 1.4.42 e 48. Brink (1971, p. 518), porém, e Kilpatrick (1990, p. 54) já viam a $A P$ como sermo. Frischer (1991, p. 87-100), em seu capítulo 4 , discutindo o gênero da $A P$, propõe classificá-la como "the mixed genre of $s e r m o$ " (p. 99). Para uma leitura satírica, o próprio Flores cita (p. 22) Golden, que teria sugerido a possibilidade de ler a $A P$ como sátira contra os Pisões. Seria, porém, importante corrigir aqui a citação ("Golden, 1996, p. 32"), já que a obra de Golden é de 1995, como consta na bibliografia (p. 157), a não ser que seja outro que não se encontra referido no elenco bibliográfico. A leitura da $A P$ como semelhante à sátira já aparece desde o séc. XVI com Escalígero (apud BRINK, 1963, p. 17): "nam et Horatius Artem quum inscripsit, adeo sine ulla docet arte, ut Satyrae propius totum opus illud esse uideatur.". Tal leitura foi retomada por Ferriss-Hill (2019, esp. p. 237-8).

11 No "Prefácio", Brunno V. G. Vieira (p. 12) apresenta a interpretação do poema como "bastante inovadora [...], confinando-o com a Sátira romana"; na contracapa, lê-se: "[...] Flores [...] também mostra os vários momentos de riso e mesmo de sátira que marcam a escrita de Horácio e fazem um contraste radical com as leituras tradicionais que viam no poema uma expressão puramente séria e quase acadêmica.".

12 Por exemplo, a comparação com o convidado satisfeito, ao fim da sátira (Sátiras 1.1.119: uti conuiua satur), como imagem do próprio gênero, imagem de saturação, é semelhante à imagem final da sanguessuga repleta de sangue (AP 476: plena cruoris hirudo). Veja-se ainda no fim de Sátiras 1.1.120 o uso do advérbio satis, em referência à saturação e ao gênero, e compare-se com o mesmo termo ao fim da AP 470 (nec satis apparet ...). Para o confronto, ver Oliensis (1998, p. 219-220) e mais recentemente Krupp (2017, p. 119-121). Por fim, já Brink

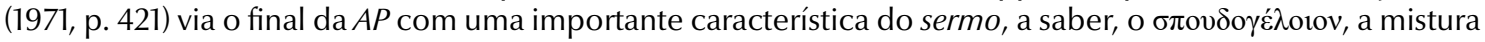
do sério com o cômico.

13 Flores afirma (p. 21) que "como epístola, ligada aos sermones e à satura, a Arte Poética horaciana é uma saturação de humores, uma curiosa composição metapoética organizada por um regulador esquivo, que quase o tempo todo evita dar preceitos inequívocos e é capaz de rir, mesmo que discretamente, de quase tudo que toca". Como na afirmação acima citada, seria preciso, a meu ver, exemplificar tudo isso. O que é exatamente satírico? É o riso? O ridículo de certos comportamentos? Quais são os preceitos equívocos e inequívocos para avaliar se "quase o tempo todo o poeta evita dar preceitos inequívocos"? 
(vv. 119-51). Ora, quase no centro desta parte (v. 139), há o famoso verso parturient montes, nascetur ridiculus mus ("parirão os montes, nascerá um ridículo rato"), que se destaca também pelo aspecto satírico. $\mathrm{O}$ adjetivo ridiculus, muito raro no verso dos poetas ${ }^{14}$, é usado por Horácio nesta forma (nominativo singular) apenas em três oportunidades ao longo de toda a sua produção: neste verso da AP e nas Sátiras $(2.3 .311 ; 2.8 .24)^{15}$. Portanto, parece-me haver também um momento satírico nesta parte. Assim, seria importante rever o gráfico esboçado, ainda que seja simplificado, pois pode passar a ideia equivocada de que não há aspectos satíricos do v. 119 ao 151.

Sobre a relação com a sátira ainda, vale a pena mencionar a proposta de Ferriss-Hill $(2019)^{16}$, que traz novos confrontos entre a AP e as Sátiras, que muito importam para a discussão de Flores. Dos vários aspectos estudados pela autora, penso que seja produtivo trazer para o debate, pelo menos, a hipótese (esp. p. 85-90) de que o muito controverso desenvolvimento sobre o drama satírico na $A P$ (vv. 220-50) tem relação com as Sátiras. Embora o drama satírico e a sátira romana sejam gêneros diversos, algumas semelhanças podem justificar a leitura de Ferriss-Hill, sobretudo ao apontar (esp. p. 86-9) no texto da $A P$ algumas prováveis retomadas ou alusões ao texto das Sátiras. Dois passos merecem destaque: ita uertere seria ludo (v. 226), que alude a Sátiras 1.1.27 (sed tamen amoto quaeramus seria ludo $)^{17}$; humili sermone $\left(\right.$ v. 229) ${ }^{18}$, que descreve também a elocução da sátira.

Sobre a tão debatida divisão da $A P$, o autor diz (p. 25) que seguirá Brink (1963), não a considerando, porém, "absoluta ou incontestável" (p. 26), com menção a outras propostas. Não há espaço aqui para discutir a questão de modo mais aprofundado, mas penso, primeiramente, que Flores não poderia deixar de, pelo menos, mencionar Martinho dos Santos (2000), artigo também ausente na bibliografia, que trata extensivamente do problema, mobilizando inúmeras fontes antigas, com proposta original de partição da $A P$ (p. 239-240). Em segundo lugar, embora anuncie adotar a tripartição de Brink, Flores recorta a seção introdutória até o v. 41, enquanto Brink (1963, p. 13) propõe o corte na

14 Entre os augustanos, só Horácio o usa.

15 Até onde pude verificar, ninguém observou esta particularidade do adjetivo ridiculus associado aos outros dois únicos usos do nominativo singular no corpus horaciano. Horácio usa ainda no acusativo singular em Sátiras 1.10.14 e Epístolas 2.1.238.

16 Ver sobre o conceito de decoro na $A P$ e a relação com as Sátiras (p. 69-80); sobre o drama satírico e possível referência às Sátiras (esp. p. 85-90); sobre o riso e a relação também com o ridículo satírico (p. 154-157).

17 A passagem satírica, por sua vez, imita Virgílio, Bucólicas 7.17: posthabui tamen illorum mea seria ludo ("deixei, contudo, minhas atividades sérias pelo jogo deles").

18 Já no v. 95 (sermone pedestri), passagem anotada por Flores também (p. 94), poderia haver alusão à elocução da própria sátira (Sátiras 2.6.17: satiris musaque pedestri). 
metade do v. 40 19 . Em seguida, Flores (p. 26) anuncia comparação - organizada em um quadro - entre a tripartição da $A P$ com outros dois autores da seguinte maneira: "[a]ssim poderíamos comparar a organização triádica apresentada por Brink em relação com o que sabemos de Neoptólemo e com as obras de Aristóteles". Contudo, a comparação e disposição em quadro são de Brink (1963, p. 138), a quem deveriam ser creditadas ${ }^{20}$. Em suma, seja no quadro (p. 26), seja antes (p. 25), seria importante corrigir a numeração da introdução e da primeira parte (dedicada ao $\pi$ oí $\mu \alpha$ ) ou apontar a divergência.

Um último ponto ainda no ensaio introdutório. O autor contrapõe (p. 22-23) Epístolas e Sátiras, em que o labor poético é referido como "um ato de escrita", aos Epodos e Odes, em que as menções ao canto e à música imperariam. Não me parece, porém, inteiramente correta a contraposição, já que, pelo menos nos Epodos, nos dois importantes momentos da discussão sobre a composição poética há referência à escrita (Epodos 11.2: scribere uersiculos) e ao livro em sua forma escrita (Epodos 14.7-8: inceptos olim, promissum carmen, iambos/ad umbilicum adducere), mencionando o cilindro em torno do qual se enrolava o papiro com o texto escrito. Há referência à música e ao canto, sem dúvida, mas quando se fala do simpósio (e.g. Epodos 9.5-6; 13.9-10) ou da composição de Anacreonte (Epodos 14.10-12). Portanto, nos Epodos, em relação ao próprio trabalho poético, Horácio faz mais referência à escrita do que ao canto ${ }^{21}$. Se assim é, a afirmação deveria ser repensada. Tal contraposição volta a ser mencionada nas notas ao v. 38 (p. 83), passo que talvez possa ser revisto também. Porém, Sátiras e Epístolas, de fato, como sermones inteiramente em hexâmetros datílicos, podem ser contrapostas a Odes e Epodos, composições caracterizadas pela polimetria.

Corrijam-se, por fim, os seguintes passos no ensaio: substituir "nestas opiniões se, no entanto, admitirmos" (p. 20) por "nestas opiniões sem, no entanto, admitirmos"; "Nial" (p. 25; mesmo erro na p. 166) por "Niall"; "aos pensamento romano" por "ao pensamento romano" (p. 27).

\footnotetext{
19 Brink, como possibilidade, admite em nota (1963, p. 13, n. 2) que a primeira parte (vv. 40-118), depois da introdução, possa ser dividida, caso alguém julgue que os vv. 42-4 sejam uma 'seção'. Veja-se também a tabela na p. 138, em que Brink marca a introdução até a metade do v. 40.

20 Apenas a relação entre a tripartição e a doutrina de Neoptólemo é referida anteriormente (p. 25) como proposta de Brink. Creio que as citações na p. 18 de Alexander Pope, André Dacier e Lehrs - o primeiro e o último não constam na bibliografia - deveriam ser referenciadas ou o autor deveria indicar também que as referências foram tomadas de Brink (1963, p. 18 e n. 1), que cita os mesmos dois versos de Pope também sem a referência ao poema (An Essay on Criticism 3.653-4), a mesma formulação de Dacier (la beauté du désordre) sem também indicar a obra e, em nota, o mesmo paradoxo de K. Lehrs (Form der Formlosigkeit), mencionando apenas que está em edição de 1869. Flores, porém, faz análise própria das passagens, com tradução rimada e em dodecassílabos dos versos de Pope. Enfim, corrija-se a citação alemã (p. 18): Forme por Form.
}

21 Com alguma discussão, é possível mencionar Epodos 17.39-40: mendaci lyra/ uoles sonari. 


\section{Texto latino e tradução}

Anuncia-se (p.31) que o texto latino adotado é da edição de Bailey (2001), que deveria ter o sobrenome como entrada na bibliografia ${ }^{22}$ por ser constantemente mencionado. Contudo, o autor menciona (p. 32) que pode divergir de Shackleton Bailey aqui e ali, seguindo outras lições e conjecturas, como as de Brink, Rudd ou outros editores e/ou comentadores. De fato, em vários passos, Flores abandona o editor da Teubner e toma lições e conjecturas diversas, discutindo-as em notas. Como demonstra Tarrant (2016, p. 293-294) ${ }^{23}$, parece que nenhuma edição das obras de Horácio se impôs ainda. Neste sentido, Flores faz bem em não seguir simplesmente o texto estabelecido por Bailey, mostrando atenção aos passos em que há discussão e dificuldades filológicas. Há, porém, alguns casos que não são assinalados e que mereceriam alguma discussão ${ }^{24}$.

Por falta de espaço, concentro-me apenas em duas passagens: 1) [...] ordinis haec uirtus erit et Venus, aut ego fallor (v. 42: "[...]todo o vigor e a Vênus da ordem, ou muito me engano" $\left.)^{25} ; 2\right)[\ldots]$ si forte necesse est/ indiciis monstrare recentibus abdita rerum./fingere cinctutis non exaudita Cethegis, (vv. 48-50: "[...]se deve/ demonstrar o segredo das coisas com termos recentes/ao forjar o inaudito para Cetegos cintudos").

Sobre a primeira passagem, não há divergência em relação ao texto editado por Bailey, mas neste caso penso, como Brink (1971, p. 129), Rudd (1989, p. 156) e outros, que melhor seria grafar uenus ("encanto"; "beleza"), com letra minúscula. Não só uenus e uirtus são termos retóricos, como anota Fedeli (1997, p. 1479-1480), mas também formam um par aliterativo e paronomástico: originariamente, uenus é a qualidade própria da mulher e uirtus, a do homem, como observa Rudd (1989, p. 156). Venus, como nome da deusa, parece menos próprio e rompe, em parte, a relação com uirtus. É possível que Flores também quisesse grafar com caixa baixa, já que em comentário aos vv. 42-5 (p. 83) o tradutor explica: "Vênus em caixa baixa é tradução de uenus, o poder de sedução da obra". Há, portanto, divergência entre a nota e os textos (o original latino e a tradução) ${ }^{26}$.

22 Ver abaixo a quarta parte sobre a bibliografia.

23 Aguarda-se a edição de R. Tarrant, que está em preparação para a coleção Oxford Classical Texts (OCT).

24 Não discuto aqui as divergências de pontuação e grafia de palavras, mas há várias diferenças não anunciadas nem explicadas em nota. E.g. Bailey adota por vezes ponto final, enquanto o texto estampado por Flores traz ponto e vírgula (vv. 18, 74, 78, 283); por vezes, dois pontos em Bailey, mas ponto final em Flores (v. 153); sodes (v. 438) em Bailey está entre vírgulas, mas em Flores, como em Brink e Rudd, não há vírgulas, etc. Sobre a grafia, além de não diferenciar o "u" vocálico do consonantal, diferentemente de Bailey, Flores adota querella (v. 98), Charybdim (v. 145), adcrescere (v. 252), adparet (v. 259; cf. v. 30: appingit), clarisue (v. 289), enquanto Bailey assim como Brink e Rudd (com exceção de querela) - tem querela, Charybdin, accrescere, apparet e clarisque.

25 As traduções da $A P$ nos dois passos são de Flores.

26 Caso opte pela minúscula, é importante pensar também sobre Veneris no v. 320. 
Em relação à segunda passagem, porém, o texto estampado parece equivocado pelo ponto final ao fim do v. 49. Bailey - e grande parte dos editores ${ }^{27}$ - tem vírgula. Como não há nota sobre o texto latino para estes versos, não está claro como Flores entende, se segue o texto de Bailey ou prefere Rostagni (1930, p. 15) e outros, que estampam ainda o et ao final do v. 49. Além disso, diferentemente de Bailey, Brink, Rudd e outros, há vírgula depois de Cethegis (v. 50), ou seja, Flores parece entender o v. 50 ligado à prótase iniciada no v. 48 (si forte ...), e não à apódose com continget, verbo que foi deixado de lado na tradução. Não é o caso de retomar aqui as discussões para decidir por esta ou aquela leitura, mas é importante que o autor revise o texto - sobretudo o ponto final no v. 49 - e comente a opção que parece divergir do texto adotado ${ }^{28}$.

A tradução, a meu ver, é a melhor parte da obra, que parece ser a primeira integral em português no que chama "hexâmetro datílico brasileiro" (p. 34), verso que tem seis tônicas, "mas, entre uma e outra, pode haver uma ou duas sílabas átonas", sendo possível assim "recriar também a variação em espondeu"29. Neste sentido, como Horácio refez em latim os metros gregos de Safo e Alceu (Odes 3.30.13-4) ou os iambos de Arquíloco (Epístolas 1.19.23-4), Flores refaz no vernáculo os vários metros horacianos, projeto que se inicia como publicação em livro ${ }^{30}$ com os hexâmetros da $A P$. Além disso, o autor esclarece (p. 34) que a proposta tradutória "visa a uma performance vocal", conhecida já por apresentações individuais ou do grupo Pecora Loca.

O tradutor observa muitos tropos, figuras e metaplasmos, reproduzindo-os com eficácia. Elenco alguns exemplos ${ }^{31}:$ 1) as anáforas em início de verso: “[...] muita comodidade trazem os anos que chegam,/muita levam os anos que partem" (vv. 1756) ${ }^{32}$; "nem o perverso Atreu cozinhe entranhas humanas,/nem se transforme Procne

27 Alguns editores, seguindo a lição de certos manuscritos, ainda colocam um et depois de rerum, que pode ter se intrometido ali pelo est no fim do verso anterior. Para a discussão de toda a passagem (vv. 48-53), é suficiente remeter a Brink (1971, p. 140-141).

28 Talvez seja importante também rever a pontuação no v. 44. Embora aqui siga o texto de Bailey com o ponto final ao fim do verso, a tradução parece concordar mais com a pontuação de outros editores.

29 Flores diz (p. 34) "que é possível fazer hexâmetro datílico brasileiro partindo das regras de metrificação alemãs", mencionando a tradução alemã da Odisseia de Homero feita por Voss no séc. XVIII. Penso, porém, que o autor poderia mencionar experimentos semelhantes em português, como o de Carlos Alberto Nunes na tradução da Ilíada, Odisseia e Eneida, ou o de Érico Nogueira ao traduzir os Idílios de Teócrito, ou mesmo indicar alguns textos já produzidos sobre o assunto, que constam na bibliografia (e.g. OLIVA NETO; NOGUEIRA, 2013).

30 O ensaio e a tradução foram publicados anteriormente como artigo (Em Tese, v. 26, p. 234-68, 2019), com ligeiras modificações.

31 Nem sempre ocorrem nos mesmos versos do original, mas no mais das vezes.

32 Flores ainda mantém o mesmo adjetivo no início do v. 169 (“[m]uitos incômodos cercam o velho..."), como no original. 
em pássaro, Cadmo em cobra" (vv. 186-7); "seja por culpa da pressa ou então por descuido completo,/seja por falta de arte, redunda em crime asqueroso" (vv. 261-2)33; 2) homeoteleuto com palavras dispostas em fim de versos sucessivos: "[...] não satisfaz o poema bonito, mas doce requinte,/para também levar onde queira a mente do ouvinte" (vv. 99-100)34; 3) a chamativa tmese: "irei me espantar se feliz di-/fere mesmo o falso amigo do amigo sincero" (vv. 424-5); 4) aliterações ou par aliterativo: "[s]iga a fama firmada ou forje um papel coerente" (v. 119); "bate no solo, busca brincar com seus pares e passa" (v. 159); "quando fora criança, censor e cricri dos menores" (v. 174); "segue um tanto pudica entre Sátiros sempre safados" (v. 233); "cordas não cedem o som que deseja a mão ou a mente" (v. 348); 5) fato que chama atenção nos hexâmetros de Horácio é o monossílabo em fim de verso, ${ }^{35}$ que não é reproduzido na mesma proporção por Flores, mas há alguns exemplos: "ou" (v. 95); "um" (v. 133); "os" (v. 286); "ó" (v. 291); "que" (v. 301); "ser" (v. 464); 6) paronomásias: "não condiz nem conduz" (v. 195); "portas abertas" (v. 199); "dosa o útil e o doce" (v. 343); "perde o perdão" (v. 355); "disto que digo" (v. 368); "via da vida" (v. 404); "a sarna assanhe" (v. 417).

O tradutor busca, sobretudo por meio do léxico, elocução coloquial (sermo): "meus

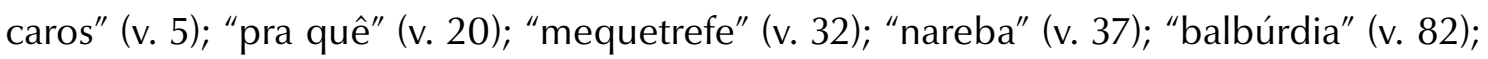
"safado" (v. 107); "que nem" (vv. 133 e 136); "cricri" (v. 174); "gingado" (v. 214); "safados" (v. 233); "chocho" (v. 337); "colado à verdade" (v. 338); "dá grana" (v. 345); “lisinho" (v. 423); ;6 "puxa-sacos" (433); "chorumelas" (v. 451); "mijou" (v. 471); "pirou" (v. 472). Além disso, o tradutor usa para a imitação do coloquial os pronomes de tratamento 'você' e 'vocês' para traduzir tu e uos; por vezes, mistura-os com o pronome possessivo de segunda pessoa, característica própria da fala (e.g. vv. 387-8).

Outra característica que chama atenção é a frequente substituição do tempo futuro no original latino pelo presente ${ }^{37}$, como "é" para erit (v. 40); "falta" para deseret (v. 41); "é dada" para dabiturque (v. 51); "renascem" e "caem" para renascentur e cadentque (v. 70); "tarda" para moraberis (v. 132); "procuro" para amabo (v. 235); "me esforço" para enitar (v. 236); “é possível” para licebit (v. 389); "prepara” para condes (v. 436); “narro” para narrabo

33 Ver ainda a tripla anáfora com poliptoto (vv. 312-4); anáforas com verso intercalado (vv. 196, 198 e 200; vv. 363 e 365).

$34 \mathrm{O}$ uso é raro em latim, ocorrendo apenas mais uma vez na $A P$ : vv. 176-7, neste caso não reproduzido na tradução.

35 Há um total de 34 monossílabos em fim de verso.

36 O uso de diminutivos, raros em Horácio, são usados para o rebaixamento da elocução (e.g. v. 231: "levinhos", e v. 378: "pouquinho").

$37 \mathrm{Em}$ alguns poucos casos, o futuro não é traduzido pelo presente, mas é deixado fora da tradução (vv. 58: licebit, e 365: placebit). 
(v. 464); "vira" e "deixa" para fiet e ponet (v. 469). O uso pode ser, por vezes, metri causa, já que o futuro do indicativo em português tem, em geral, uma sílaba a mais do que o presente do indicativo; é uso ainda coloquial ("volto logo" por "voltarei logo"), que se adéqua ao projeto da tradução.

Contudo, em alguns versos a substituição gera diferenças de sentido que poderiam ser evitadas. Dos cinco verbos no futuro do indicativo nos vv. 136-139 quatro são traduzidos pelo presente ${ }^{38}$. Para a discussão, atenho-me a dois passos que merecem mais discussão: v. 137: '[...] fortunam Priami cantabo et nobile bellum' ("'...] fado de Príamo quero cantar e a ínclita guerra'"), e v. 139: [...] parturient montes, nascetur ridiculus mus ("[...] montes podem parir: nascerá um ridículo rato"). Nestes dois casos, mais do que a substituição do futuro do indicativo pelo presente do indicativo, o tradutor usa dois verbos auxiliares modais: cantabo ('cantarei') é traduzido por "quero cantar" e parturient ('parirão') por "podem parir". A modalização altera a força do ridículo sobre o poeta cíclico: no primeiro, mais do que o desejo de cantar, o prometedor afirma que cantará; no segundo, mais do que a possibilidade de parir, os montes vão parir ${ }^{39}$. Sem prejuízo do metro, "quero" poderia ser substituído por "vou" e "podem" por "vão".

Um erro, porém, que precisaria ser corrigido é a tradução de lēuis. O tradutor toma o lēuis ("polido") pelo lěuis ("leve"). Por exemplo, no v. 26, lēuia é traduzido como "a leveza", comentando ainda nas notas (p. 81): "o breve se torna obscuro, o leve se torna fraco, o grandioso fica empolado ..."; ${ }^{40}$ no v. 332, a tradução para lēui seruanda cupresso é "guardar no leve cipreste". O cipreste não é propriamente uma árvore leve, mas a madeira era usada para fazer uma espécie de baú, em que se conservavam coisas, por ser muito duradoura. Para isso, ela era bem polida. O único lĕuis na $A P$ é no v. 231: effutire leuis indigna tragoedia uersus, traduzido como "[...] pois a tragédia jamais tagarela em versos levinhos".

Por fim, corrija-se "farto" (v. 476) por "farta", a sanguessuga cheia ou farta de sangue (plena cruoris hirudo).

\section{Notas}

As notas são para blocos de versos ou um único verso, comentando escolhas textuais que divergem da edição adotada, como para o v. 32 (p. 82); por vezes, servindo para

38 Um deles é presente do subjuntivo, formando o imperativo negativo (v. 136: "[...] nem comece").

39 Especificamente para o v. 139, seria importante ainda manter o futuro devido à variação com o presente parturiunt, que existe em alguns manuscritos e autores, como Jerônimo (adv. Iovin. 1.1) e o ex-ministro Sérgio Moro.

40 Para o estilo polido, ver os comentários de Brink (1971, p. 109-110). 
explicar a tradução, como no caso da expressão callida iunctura, traduzida por "costura sagaz" (p. 84); esclarecendo, sobretudo para o público leigo, quem são os personagens históricos, como os escritores referidos entre os vv. 54-56 (p. 86-87); apontando modelos e alusões, como a célebre passagem iliádica (6.146-9), em que se comparam as gerações das folhas e as dos homens, para os vv. 60-2 (p. 87); relacionando passagens da AP com outras obras do próprio Horácio, como a expressão sermone pedestri (v. 95), que é próxima à musa pedestri, usada para descrever a elocução satírica em Sátiras 2.6 .17 (p. 94); entre outras finalidades. São, portanto, úteis para a leitura do público leigo ou mesmo do especializado. Há, porém, nesta parte vários pequenos problemas, listados aqui ao fim desta seção. Na sequência, discuto apenas duas passagens que talvez mereçam revisão: a sequência dos vv. 73 e 88 e o v. 467.

$\mathrm{Na}$ anotação para os vv. 73-88 (p. 90-92), ao iniciar a explicação, Flores afirma (p. 90): "Horácio trata agora das relações entre forma e conteúdo nos gêneros [...] da poesia grega arcaica associados tradicionalmente ao seu suposto inventor [...], seguindo a ordem pindárica (Olímpicas, 2.2) de deus, herói, homem.". Não está claro como Horácio usou a ordem pindárica na passagem da $A P$ em que se descrevem os gêneros (vv. 7385): epopeia (vv. 73-74); elegia [e epigrama] (vv. 75-78); iambo (v. 79); lírica (vv. 83-85). Em geral, a sequência pindárica 'deus, herói e homem' pode ser associada à sequência helenística das espécies líricas que o poeta descreve apenas na parte final (vv. 83-85): hino (aos deuses), encômio (aos filhos de deuses), epinício (aos homens vitoriosos nas competições; por vezes, descendentes dos deuses), erótica (às amadas e amados) e simpótica (ao vinho e aos banquetes dos homens).

Em seguida, no comentário à elegia e ao epigrama, o autor afirma (p. 91): "[...] em Roma os nomes mais conhecidos do epigrama e da elegia na época eram Catulo, Propércio, Tibulo e Ovídio (talvez em começo de carreira).". Talvez fosse importante distinguir Catulo dos elegíacos augustanos, que são de outra geração. Ademais, embora alguns poucos versos tenham sobrevivido, Galo era nome mais do que conhecido, sempre mencionado pelos outros elegíacos (ver Ovídio, Tristezas 4.10.53-4), considerado o fundador da elegia erótica em Roma, e pelo bucólico Virgílio (ver Bucólicas 6.64 e 10.2-10).

Na passagem sobre o iambo, logo em seguida (p. 91), não está clara a discordância presente em Aristóteles, quando diz: "Arquíloco apresenta o iambo como poesia de invectiva e ataque, em discordância do que lemos em Aristóteles, que atribui a invenção do metro a Homero no Margites [...].". Na primeira oração do período, o autor trata do iambo como gênero; na segunda, do iambo como metro. Poderia haver discordância entre o que Aristóteles afirma no cap. 4 da Poética, atribuindo o início do vitupério a Homero, e a atribuição do início do gênero por outros, como Horácio, a Arquíloco. Se for isto, seria importante rever o texto. 
Por fim, comentando os versos sobre a lírica (p. 92), Flores descreve as espécies, associando-as a determinados poetas: "temos a lírica elevada dórica dos hinos, epinícios e encômios de Píndaro ("deuses e filhos de deuses, / de ${ }^{41}$ vencedores na luta"), da lírica eólica média dos poemas eróticos e simpóticos de Alceu e Safo ("aflições dos jovens") e talvez até mesmo de Anacreonte ("versos de vinhos libertos"), por sua métrica mais simples.". Não parece precisa a associação, já que Alceu, Safo $^{42}$ e Anacreonte também compuseram hinos; Alceu é muito conhecido pelos poemas em que trata do vinho (aliás, imitados por Horácio, como em Odes 1.18; 1.37 etc.). Por fim, seria importante dizer que na tradução do v. 85 inseriu-se o termo 'versos': o sintagma uina libera (simplesmente, "vinhos libertadores", "que libertam [dos cuidados]") é traduzido como "versos de vinhos libertos". A ambiguidade sobre o adjetivo - são os versos ou vinhos libertos? - é desfeita nas notas, quando o autor afirma (p. 92): "[...] os versos do vinho aparecem como libertos [...]". Tal como se coloca parece que há um jogo entre os versos libertos e o deus Dioniso. Contudo, no original, não há 'versos', e o adjetivo libera ("libertadores") caracteriza uina ("vinhos"), que estabelece um jogo com o nome romano do deus, Liber.

Na última nota, para o v. 467 (p. 137), afirma-se: “[...] este é o único verso de todos os sermones horacianos a terminar em espondeu [...].". Na verdade, trata-se de um hexâmetro espondaico, em que, não o último, mas o quinto e penúltimo pé é um espondeu. Além disso, ao propor explicação para este uso único nos sermones ${ }^{43}$, Flores (p.137) continua: "Rudd [1989:227] ${ }^{44}$ não consegue compreender o motivo dessa anomalia, mas creio que ela pode ser lida como metáfora da morte do próprio verso, deslocado de sua regra.". Julgo que a interpretação metafórica é equivocada. Primeiramente, embora os versos espondaicos sejam raros entre os augustanos ${ }^{45}$, fazem parte da possibilidade de constituição do hexâmetro. Assim, é prática frequente, por exemplo, em Catulo (no Poema 64, com 408 versos, há 30 hexâmetros espondaicos), que está imitando prática grega $^{46}$. Não raro, nos hexâmetros espondaicos, há termos gregos. Ora, no verso horaciano

\footnotetext{
41 Na tradução do v. 84 (p. 47), "deu" no lugar de "de".

42 Em Odes 4.1, por exemplo, Horácio imita, como bem se sabe, o hino de Safo a Afrodite (fr. 1 V.).

43 Nos Epodos e nas Odes, há um total de quatro ocorrências: Epodos 13.9; 16.17 e 29; Odes 1.28.21.

44 "The spondaic ending is the only one in H.'s sermones. Its purpose here has not been explained.".

45 Para ficar em alguns exemplos, ver Virgílio, Bucólicas 4.49; 5.38; Geórgicas 1.221; Eneida 3.517; 8.679; Ovídio, Metamorfoses $1.14 ; 1.193$.

46 Em Calímaco, um a cada onze versos hexâmetros é espondaico; em Arato, um a cada seis (FORDYCE, 1973, p. 277). São frequentes também em Lucrécio (e.g. Da natureza das coisas 3.191, 198, 249, 417, 545 e 907 ), embora sejam bem menos numerosos do que nos autores gregos.
} 
não há palavras gregas, mas, como anota Brink (1971, p. 428)47, há helenismo sintático em idem ... occidenti, o que corrobora, portanto, o helenismo métrico com o hexâmetro espondaico $^{48}$.

Resta, por fim, a dúvida sobre a emulação do ritmo anunciada, já que a quinta sede na tradução é uma sequência de três sílabas (forte, fraca e fraca): paréc(e) assasíno (entre as duas fortes, marcadas em negrito, há duas fracas ["-c(e) assa-"], que equivalem, junto com a primeira forte ["-re-"], ao pé dáctilo, ausente no quinto pé do verso espondaico). Dever-se-ia, portanto, explicar melhor como se deu a "emulação do ritmo", pois o que chama a atenção no verso latino é o fato de ter o espondeu no quinto pé.

Corrijam-se os seguintes detalhes: substituir "Sátiras 1.1.160-7" (p. 81) por "Sátiras 1.1.106-7"; "Odes 1.32.9" (p. 82) por "Odes 1.32.11-12"; "porque [...]?" (p. 85) por "por que [...]?"; na nota aos vv. 48-53 (p. 85), depois de anunciar que há três modos de criar palavras novas, elenca inicialmente por letra "a)" o primeiro modo, mas não usa as letras "b)" e "c)" na sequência; substituir "retomado" (p. 87) por "retomada"; "da sátiras" (p. 94) por "da sátira" ou "de sátira"; "o quadro idades" (p. 104) por "o quadro de idades" ou "as quatro idades"; "uma vez que é escritor de dramas satíricos" (p. 111) por "uma vez que não é escritor de dramas satíricos"; "Quérlio" (p. 124) por "Quérilo"; "Sátiras, 1.10.95" (p. 125) por "Sátiras, 1.10.85"; colocar ponto final depois de "(Amores, 1.15.14)"; substituir "Epodos, 12" (p. 137) por "Epodos, 6".

\section{Bibliografia}

Antes do elenco bibliográfico, o autor adverte: “[...] esta é a lista completa de obras que venho consultando desde 2010 para o estudo e a tradução das obras completas de Quinto Horácio Flaco. Como toda empreitada sobre um autor clássico da Antiguidade, permanecerá inacabada, por mais extensa que seja.". Não se trata, portanto, de obras citadas no livro, como é usual, mas talvez seja uma lista que deverá servir para as próximas publicações. Seja como for, parece-me evidente que possam faltar alguns estudos em qualquer edição de uma única obra de Horácio. O que dizer, então, de uma bibliografia

47 Já antes comentava Rostagni (1930, p. 131): “[...] il costrutto idem facit occidenti è alla greca: $\tau \alpha$ to $\pi$ oteĩ $\tau \tilde{\omega}$

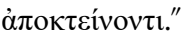

48 Os helenismos, métrico e sintático, ocorrem logo depois de Horácio relatar a morte do poeta grego Empédocles (vv. 463-466; v. 465: Empedocles). 
para estudo de toda a obra do poeta latino? Embora seja extensa a bibliografia ${ }^{49}$, estão ausentes muitos títulos fundamentais para o estudo de toda a obra horaciana. Não cabe mencioná-los aqui, mas alguém interessado, por exemplo, nos Epodos não encontrará os comentários mais importantes; Kirk Freudenburg, um dos principais nomes no estudo das Sátiras, não consta; para o estudo das Odes, faltam algumas monografias e comentários que já têm longa fortuna. Nota-se também a pequena quantidade de artigos sobre a obra de Horácio. Mesmo em relação à $A P$ a bibliografia é bastante incompleta. Poderia ser muito útil, a meu ver, uma bibliografia com os estudos da $A P$, ainda que faltassem alguns - sempre há de faltar - e não fossem citados no corpo do livro. Assim, embora extensa, estão ausentes muitos títulos fundamentais, que facilmente se encontram on-line, vários gratuitamente.

À parte a pertinência ou não da longa bibliografia, dividida em duas partes, "[...] edições críticas, traduções, comentários e escólios de Horácio e gramáticos e metricistas antigos" (p. 143-147) e "[...] estudos e outras obras literárias" (p. 147-170), é necessário que se faça uma cuidadosa revisão, pois, além de problemas com a organização de acordo com os critérios estabelecidos, há vários erros nos títulos e atribuições equivocadas. $\mathrm{Na}$ sequência, enumero alguns exemplos dos problemas:

1) inconsistência na apresentação dos editores e tradutores: ora o nome do tradutor é referido na entrada (p. 144): "FALCÃO, Pedro Braga. HORÁCIO: Odes [...]", ora a entrada é pelo nome do poeta latino (p. 144): "HORÁCIO. ${ }^{50}$ Odas, Canto secular, Epodos. Introducción general, traducción y notas de José Luis Moralejo [...]"; a edição da Oxford Classical Texts de 1901 tem como entrada o nome do editor (p. 147): "WICKHAM, Edward C. [...]", mas as duas edições da Teubner, a mais antiga de F. Klingner (1959) e a mais recente de S. Bailey (2001), são introduzidas pelo nome do poeta latino, de modos diversos: a primeira (p. 146): “Q. HORATI FLACCI OPERA [...]”, e a segunda (p. 144): “HORATIUS OPERA [...]";

\footnotetext{
49 Penso que seria mais útil, por exemplo, agrupar as obras sobre tradução ou traduções poéticas, que formam um grande grupo: Haroldo de Campos, com 15 títulos (p. 151-152), o autor com mais obras na bibliografia; Henri Meschonnic, com 9 títulos (p. 162); Philippe Brunet (p. 150), Mauricio Mendonça Cardozo (p. 152), alguns títulos do próprio Flores (p. 155-156), Mauri Furlan (p. 156), Rodrigo Tadeu Gonçalves (p. 157), John Milton (p. 162), João Angelo Oliva Neto (p. 163-164), José Paulo Paes (p. 164), Paulo Rónai (p. 166), Lucia Santaella (p.166), Marcelo Tápia (p.167-168), entre outros. Assim, aqueles interessados em tal assunto teriam um material de consulta, mais organizado, sem se perder em elenco vasto e bastante heterogêneo. Seria importante, em algum momento do projeto, explicitar qual a relação de alguns autores ou títulos com o estudo e tradução de Horácio, tais como, Gilles Deleuze (p. 154), Jacques Derrida (p. 154), Umberto Eco (p. 154-155; à exceção do livro sobre tradução), Marshall McLuhan (p. 161), Luiz Tatit (p. 168), Paul Zumthor (p. 170) e Slavoj Zizek (p. 170), embora este último seja citado na obra (p. 13), mas sem a referência precisa, o que exigiria distinguir Zizek (2008a e 2008b).
}

50 Corrija-se "HORÁCIO" por “HORACIO" nas duas entradas para a obra de José Luis Moralejo. 
2) atribuições equivocadas: "KILPATRICK, Ross S. Q. Horatius Flaccus [...]" (p. 145); "NÓBREGA, Vandick Londres da. A Commentary on Horace, Odes, Book 2, Oxford [...]" (p. 145); "BÜCHNER, Karl. Sextus Propertius: The Augustan Elegist [...]" (p. 150); "CAVALLO, Guglielmo; FEDELI, Paolo; GIARDINA, Andrea (Eds.). Properzio, elegie libro /l [...]" (p. 152) ${ }^{51}$; as três obras em português atribuídas a HARRISON (p. 158); "JAKOBSON, Roman. Le livre de Catulle [...]" (p. 159)52; "OLIVA NETO, João Angelo; NOGUEIRA, Érico. O livro de Catulo $[\ldots]^{\prime \prime}(\text { p. 164) })^{53}$.

3) obras da primeira parte que talvez devessem estar na segunda e vice-versa: as duas obras de Ross Kilpatrick (p. 145), embora ao fim haja traduções, são estudos monográficos, assim como Dante Tringali (p. 147). Se, porém, estão ali pelas traduções, Francisco Achcar (p. 147) também traz traduções ao fim da obra, mas é claramente colocado entre os estudos. Por outro lado, Brunno V. G. Vieira (p. 169), que é apenas tradução dos cem primeiros versos da $A P$, está equivocadamente entre os estudos, assim como a tradução de H. Rushton Fairclough (Horace: Satires, Epistles and Ars Poetica) para a coleção Loeb (p. 155) ou a edição de Niall Rudd para a coleção da Cambridge (p. 166; repete-se na p. 146);

4) falta de indicação da editora ou cidade e erros ortográficos: não se informa a editora da obra de Rostagni (p. 146), que é Chiantore, edição de 1930; reeditada pela Loescher, edição de 1986; informa-se equivocadamente o primeiro nome de Rostagni: substituir "Alberto" por "Augusto". Corrijam-se nos títulos: em Flores, 2010 (p. 156), substituir "lirica" por "lírica"; em Jensen, 1923 (p. 159), substituir "di GEdichte" por "die Gedichte"; em Pascoli, 1948 (p. 164), substituir "opera" por "opere"; faltou indicar o nome em Riese, 1866 (p. 166); em Rossi, 2000 (p. 166), não são indicadas a cidade e a editora: Roma: Edizioni Quasar.

Porfim, quando há obras do mesmo autor, o critério adotado parece ser cronológico, da mais recente para a mais antiga, mas em muitos casos não se observa tal critério.

A nova tradução da $A P$ de Horácio, a primeira no chamado hexâmetro datílico brasileiro, realizada por Guilherme Gontijo Flores, com introdução e notas, junta-se a outras traduções, em verso e prosa, desta obra fundamental do poeta latino. Certamente, é mais uma boa oportunidade para o público, leigo ou especializado, que deseja conhecer ou se aprofundar na obra horaciana. O volume, porém, embora tenha méritos - sobretudo em seu projeto tradutório -, necessita de extensa e minuciosa revisão, como

51 Só FEDELI, Paolo.

52 Coloca-se sem indicação de cidade, mas é Lausanne.

53 Só OLIVA NETO, João Angelo. 
procurei evidenciar aqui. Para a segunda edição, seria ainda importante rever algumas afirmações, voltando aos estudos já mencionados e confrontando-os com outros mais recentes que fizeram avanços importantes nas discussões da $A P$.

\section{Agradecimentos}

Agradeço ao parecerista da revista as sugestões e correções.

\section{Referências}

ARMSTRONG, D. The Addressees of the Ars poetica: Herculaneum, the Pisones and Epicurean Protreptic, MD ('Mega nepios: Il destinatario nell'epos didascalico'), v. 31, p. 185-230, 1993.

BAILEY, D. R. S. Q. Horati Flacci Opera. 4. ed. München/Leipzig: Teubner, 2001.

BRINK, C. O. Horace on Poetry: The 'Ars Poetica'. Cambridge: Cambridge University Press, 1971.

BRINK, C. O. Horace on Poetry. Cambridge: Cambridge University Press, 1963.

BECKER, C. Das Spätwerk des Horaz. Göttingen: Vandenhoeck \& Ruprecht, 1963.

FEDELI, P. Q. Orazio Flacco: Le opere. II, t. quarto: le Epistole, I'Arte Poetica. Roma: Istituto Poligrafico e Zecca dello Stato, 1997.

FERRISS-HILL, J. Horace's Ars Poetica. Family, Friendship, and the Art of Living. Princeton \& Oxford: Princeton University Press, 2019.

FORDYCE, C. J. Catullus: A Commentary. Oxford: Clarendon Press, 1973.

FRISCHER, B. Shifting Paradigms: New Approaches to Horace's Ars Poetica, Atlanta (GA): Scholars Press, 1991.

GEUE, T. Editing the Opposition: Horace's Ars Politica", MD ('New Approaches to Horace's Ars poetica), v. 72, p. 143-172, 2014. 
- Arte Poética (resenha)

HARDIE, P. The Ars Poetica and the Poetics of Didactic", MD ('New Approaches to Horace's Ars poetica ), v. 72, p. 43-54, 2014.

HOLDER, A. Pomponi Porfyrionis. Commentum in Horatium Flaccum. New York: Arno Press, 1979.

KILPATRICK, R. S. The Poetry of Criticism: Horace, Epistles II and Ars Poetica. Edmonton: University of Alberta Press, 1990.

KRUPP, J. A Sense of an Ending: Closure in Horace's Ars Poetica (453-76), Phaos, v. 17, p. 101-124, 2017.

MARTINHO DOS SANTOS, M. O monstrum da Arte poética de Horácio, Letras Clássicas, v. 4, p. 191-265, 2000.

MAYER, R. Bernard Frischer: Shifting Paradigms: New Approaches to Horace's Ars Poetica. (American Classical Studies, 27.) Pp. xiii + 158; 3 ills. Atlanta, GA: Scholars Press, 1991, CR, v. 42, p. 442, 1992.

MUECKE, F. Epistles Book II and Epistle to the Pisones ('Ars Poetica') by Horace and N. Rudd; The Poetry ofCriticism: Horace. Epistles II and Ars Poetica by R. S. Kilpatrick; Shifting Paradigms: New Approaches to Horace's Ars Poetica by B. Frischer, JRS, v. 83, p. 213-214, 1993.

OLIENSIS, E. Horace and the Rhetoric of Authority. Cambridge: Cambridge University Press, 1998.

OLIVA NETO, J. A.; NOGUEIRA, É. O hexâmetro dactílico vernáculo antes de Carlos Alberto Nunes, Scientia traductionis, v. 13, p. 295-311, 2013.

ROSTAGNI, A. Orazio. Arte Poetica. Torino: Chiantore, 1930.

RUDD, N. Horace: Epistles Book II and Epistle to the Pisones ('Ars Poetica'). Cambridge: Cambridge University Press, 1989.

SANTIROCCO, M. The Maecenas Odes, TAPhA, v. 114, p. 241-253, 1984. 
TARRANT, R. A new critical edition of Horace. In: HUNTER, R.; OAKLEY, S. P. Latin Literature and its Transmission. Cambridge: Cambridge University Press, 2016. p. 291321.

COMO CITAR ESTA RESENHA: HASEGAWA, Alexandre Pinheiro. Resenha de FLORES, G. G. Horácio. Arte Poética. Tradução, introdução e notas de Guilherme Gontijo Flores. Belo Horizonte: Autêntica Editora, 2020. Revista do GEL, v. 18, n. 2, p. 218-236, 2021. Disponível em: https://revistadogel.gel.org.br/

Submetido em: 02/04/2021 | Aceito em: 16/04/2021. 